\title{
POR UMA EDUCAÇÃO INTERCULTURAL
}

FRANCIS MARY SOARES CORREIA DA ROSA ${ }^{1}$

$U N E B$

\section{RESENHA}

MUNDURUKU, Daniel. O Banquete dos Deuses: conversa sobre a origem da cultura brasileira. $2^{a}$ ed. São Paulo: Global, 2009. 103 p.

Na obra O Banquete dos Deuses: conversa sobre a origem e a cultura brasileira, o autor Daniel Munduruku, mestre em Antropologia Social pela Universidade de São Paulo, doutor em Educação pela mesma instituição e pós-doutorando em Literatura pela Universidade Estadual de São Carlos, discorre em tom ensaístico sobre o caráter transcultural e holístico da cultura e práticas ancestrais dos grupos indígenas brasileiros, refletindo, inclusive, sobre as possibilidades e contribuições dessa herança ancestral no âmbito da educação, principalmente no que tange a uma prática educativa preocupada e perpassada por uma ética da alteridade.

\footnotetext{
${ }^{1}$ É aluna regular do Mestrado em Critica Cultural e Pós-Crítica da Universidade Estadual da Bahia na linha de pesquisa Margens das Literatura, onde estuda a produção literária de Olívio Jekupé como uma literatura menor. É membro do grupo de pesquisa Lingua(gem) e Crítica Cultural na linha Literatura, subalternidade e micropolítica e Teorias contemporâneas: recepção, mapas e poiéticas (Diretório 5.0 CNPq). Graduou-se em Licenciatura Plena em História pela Universidade do Estado da Bahia (2005) e possui Especialização em Filosofia Contemporânea pela Universidade Estadual de Feira de Santana (2010). Possui pós-graduação (modalidade atualização) em Educação Ambiental pela Universidade Federal da Bahia (2013) e gradua-se em Administração de Empresas pela Universidade Estadual de Feira de Santana e em Filosofia pelo Centro Universitário Claretiano. Além de mestranda, cursa pós-graduação em Ensino de Filosofia no Ensino Médio (Universidade Federal da Bahia). E-mail: francismrosa@hotmail.com.
} 
A presente edição resenhada - a saber, a segunda edição, publicada em 2009 - encontra-se justamente no bojo das discussões da implantação da lei $n^{\circ} 11.645$, sancionada em 10 de março de 2008, que dispõe sobre a obrigatoriedade do ensino da cultura e história indígena. Neste contexto, a obra desdobra-se em dois momentos ao longo dos seus onze capítulos, que buscam ser um referencial e um suporte aos educadores e interessados em promover um revisionismo histórico sobre o lugar e a imagem dos indígenas na tradição ocidental brasileira e nas próprias instituições escolares, assim como, também, ensaiar um deslocamento dos valores tradicionais ocidentais sobre a educação por meio de uma interação com a percepção holística de mundo dos povos indígenas brasileiros.

Lançando mão de um revisionismo antropológico, Munduruku nos propõe um mergulho na "alma" e "espiritualidade" indígena, ao nos oferecer logo nos primeiros capítulos um ensaio autobiográfico de sua própria condição de ser "índio" - termo que ator adverte ser equivocado e pautado em estereótipos, por isso mesmo sendo substituído ao longo da obra por indígena - demarcando as dificuldades, os preconceitos vividos e como a relação com seu avô foi de suma importância para a compreensão do seu lugar no mundo e de sua própria condição indígena. É aí, justamente em sua própria ancestralidade, presente na figura do avô, que o autor costura o deslocamento necessário para aqueles que querem se aproximar da sabedoria indígena e de seu modo de ser.

Para Daniel Munduruku, a imagem de "selvagem" e de "incapaz" atribuída aos grupos indígenas diz respeito justamente a uma construção etnocêntrica e unilateral da alteridade, e esta mediação é balizada em uma visão de mundo que toma como unicamente válidos os seus próprios pressupostos, relegando aos indígenas uma imagem de um outro destituído de história, de escrita, estático em um passado em que foi adicionado mediante sua relação com o colonizador.

Tal concepção foi continuamente reproduzida nos livros didáticos e é, segundo o autor, a principal responsável por fazer gerações acreditarem em uma imagem estereotipada do indígena e, portanto, incompleta, ao mesmo tempo que tomam como positivo o processo de colonização e reforçam um modelo marcado pelo evolucionismo 
cultural, por um positivismo acrítico e pelo silenciamento de uma gama de tradições e da diversidade indígena em todas as suas formas: linguística, cultural e histórica.

Desta forma, os capítulos que se seguem destacam o valor que uma relação de alteridade representada na recusa ao lugar direcionado aos indígenas na atualidade (seja nos meios de comunicação, nas obras didáticas, na literatura canônica, no imaginário etc.) e nas relações institucionais e políticas no que concerne ao direito a uma cidadania transnacional que é atualmente negada às nações nativas pela tutelagem, que desqualifica tais sociedades de possuírem autonomia e autodeterminação sobre seu destino.

Nos capítulos quatro e cinco, que compõem a primeira parte do livro, dedicada a apresentar ao leitor o corpus identitário indígena, o autor destaca os pressupostos de uma identidade comum entre todas as sociedades tradicionais, assim como sua forma holística de enxergar o mundo e a natureza. Tal pressuposto, segundo Munduruku, é a compreensão da terra como elemento sagrado e originário de toda a vida, ao mesmo tempo em que o real e o sagrado coexistem em um mesmo plano, colocando a vida em todas as suas formas como presentes da mãe Terra, os grupos nativos a festejam e agradecem tal presente com os cantos, danças e a imitação das cores da natureza na pintura dos seus corpos. Essa atitude de agradecimento, de alegria e respeito a natureza é que alimenta a divindade do mundo, é o que torna a todos o banquete para os deuses.

Para o autor, não somente os que festejam a vida em rituais ou mesmo somente os nativos podem se tornar alimento para o divino, mas também todos aqueles que agem com esperança, que educam com o compromisso ético e transcultural e os que olham para o diferente de si embebidos de outridade.

É justamente este fundamento da alteridade, inspirado pela maneira indígena de educar, que é tomado como pressuposto básico das relações interpessoais e é aprofundado na segunda parte do livro, dedicada a pensar um dispositivo educacional que subverta uma ótica ocidental centrada na compartimentalização e disciplinarização do conhecimento, assim como descaracterização da história individual do educando. 
Nos capítulos seis a oito, o autor pontua sobre a necessidade de colocar "os indígenas no centro da reflexão sobre a educação" (2009, p. 66), pois, ao compreender o processo pelo qual as sociedades nativas são discriminadas e ignoradas, pode-se fazer uma ponte sobre a forma que ocorre a educação tradicional no caso brasileiro, onde, segundo o autor, se despreza o outro e se educa para o individualismo extremo e para a dominação da natureza, priorizando a simples reprodução da cultura letrada do Ocidente (2009, p. 79). Desta forma, as sociedades indígenas representam um contraponto a esse tipo de modelo pedagógico largamente reproduzido nos quatro cantos do cenário nacional, pois, mediante $\mathrm{o}$ autor, a educação nativa prioriza a necessidade de olhar para fora, de entender o corpo como sagrado e, portanto, parte indissociável da aprendizagem, de encarar o outro em sua diferença e de reconhecer sua ancestralidade e o papel de cada um na continuidade da vida e da tradição.

A fim de esclarecer este possível diálogo entre o modelo tradicional de educação e a maneira de educar das sociedades nativas, Munduruku traz, ao final da obra, em um capitulo intitulado Sobre piolhos e outros afagos, sua definição de educação indígena: "A sociedade indígena educa tendo uma concepção holística. Todos educam, todos são responsáveis pelas crianças, fato que impede que recaia sobre alguém - inclusive os pais - o cuidado delas" (2009, p. 80). E ainda complementa mais à frente que é preciso uma educação imbuída de valores éticos, que resgate o poder de fazer sonhar, de educar de forma afetuosa e com confiança tal como deitar a cabeça no colo de alguém e deixar que the cate os piolhos. E como ressalta o autor: "...pouco importa se os piolhos são apenas imaginários!" (2009, p. 82). Ao final da obra, encontramos um conjunto de anexos de vital importância para a construção de um trabalho em sintonia com a lei 11.645, com indicações bibliográficas e textos de trabalho de vários autores indígenas.

Daniel Munduruku, nesta obra, assim como em outras produções acadêmicas e artigos, tem como objetivo principal fornecer um material introdutório para que pais e educadores possam dialogar com uma educação transcultural e com compromisso ético. Contribui, desta forma, para fortalecer uma relação de troca de saberes entre povos de 
culturas diferentes e de convite a uma constante revisão dos valores antropológicos aos quais estamos acostumados. Abrir mão de um mundo que sacrifica a diferença em busca do significado institucionalizado ou ordinariamente aceito pela tradição não é tarefa fácil para um ocidentalizado.

Como destaca Viveiros de Castro (2010), recusar uma condição de ocidental que nos impede de perceber que cada sociedade postula e busca soluções para seus próprios problemas é um passo fundamental para compreender a falibilidade de um ideal de humanidade, universal e centralizado em seu próprio anthropos, que nos impede de aproximarmo-nos de uma relação de alteridade com os outros humanos (e os animais também) em toda sua diferença.

Por isso mesmo, uma obra que procura destronar valores e nos contar um pouco do outro lado é fundamental na tarefa de instrumentalizar uma existência transnacional, de elucidar o ethos e a tradição de um povo, de mostrar as possibilidades de existência e as humanidades possíveis.

\section{Referências bibliográficas}

MUNDURUKU, Daniel. O Banquete dos Deuses: conversa sobre a origem da cultura brasileira. São Paulo: Global, 2009.

VIVEIROS DE CASTRO, Eduardo Batalha. O Anti-Narciso: lugar e função da Antropologia no mundo contemporâneo. Revista Brasileira de Psicanálise, São Paulo, v. $44, \quad$ n. $4, \quad$ p. 15-26, $2010 . \quad$ Disponível em: http://pepsic.bvsalud.org/scielo.php?script=sci_arttext\&pid=S0486641X2010000400002\&lng=pt\&nrm=iso. Acesso em: 09 jan. 2015.

Recebido em: 03/03/2015* Aprovado em: 24/04/2015* Publicado em: 30/06/2015 